\title{
Edrophonium priming alters the course of neuromuscular recovery from a pipecuronium neuromuscular blockade
}

This study was designed to investigate the effect of divided administration of edrophonium on the course of neuromuscular recovery from a pipecuronium neuromuscular blockade. During thiopentone-nitrous oxide-halothane anaesthesia 48 patients were given pipecuronium $70 \mu \mathrm{g} \cdot \mathrm{kg}^{-1}$. Patients were randomly assigned to one of four groups ( $n=12$ in each) to receive either edrophonium I mg $\mathrm{kg}^{-1}$ (Groups I and II) or edrophonium $0.75 \mathrm{mg} \cdot \mathrm{kg}^{-1}$ (Groups III and IV). In Groups I and III (single-dose groups), edrophonium was administered as a single bolus dose. In Groups II and IV (divided-dose groups) edrophonium was administered as an initial dose of 0.25 $\mathrm{mg} \cdot \mathrm{kg}^{-1}$ followed three minutes later by either 0.75 or 0.50 $m g \cdot \mathrm{kg}^{-1}$ respectively. Reversal was attempted at $20 \%$ spontaneous recovery of twitch height. Administration of edrophonium in divided doses (Groups (I and $I V$ ) accelerated the reversal of the pipecuronium neuromuscular blockade. At ten minutes post-reversal, train-of-four (TOF) ratio recovery reached 0.75 or more in 12 (100\%) and in ren (83\%) patients in Groups // and $I V$ respectively. Similarly, times to attain a TOF of 0.75 (SEM) were shorter in the divided-dose groups than in the single-dose

\section{Key words}

ANTAGONISTS, NEUROMUSCULAR RELAXANTS: edrophonium; MONITORING, NEUROMUSCULAR: train-of-four; NEUROMUSCULAR RELAXANTS: pipecuronium; PHARMACODYNAMICS: priming principle.

From the Department of Critical Care Medicine, Faculty of Medicine and Health Sciences, United Arab Emirates University, United Arab Emirates, and the *Department of Anaesthesia, Al-Kasr El-Ani Hospital, Cairo University, Egypt.

Address Correspondence to: Dr. Mohamed Naguib, Department of Critical Care Medicine, Faculty of Medicine and Health Sciences, United Arab Emirates University, P.O. Box 17666, Al Ain, United Arab Emirates.

Accepted for publication 12th April, 1991 .
Mohamed Naguib MB BCh MSc FFARCSI MD, Mohamed Abdulatif MB BCh MSc MD* groups $(P<0.05)$, being 354.5 (38.7) and $398.3(49.1)$ sec in Groups II and IV vs $705.4(66.6)$ and $65 I .2(54.3) \mathrm{sec}$ in Groups $I$ and III respectively. Time was counted from the first administration of edrophonium. It is concluded that administration of edrophonium in divided doses produced a faster reversal of residual pipecuronium-induced neuromuscular blockade than single bolus administration. Also, administration in divided doses reduced the requirements of edrophonium needed for reversal of pipecuronium neuromuscular blockade.

Nous avons voulu évaluer l'effet de la fragmentation de doses d'édrophonium injectées pendant la phase de récupération d'un bloc neuromusculaire au pipécuronium. Nous injections d'abord d 48 patients, randomisés en quatre groupes de 12,70 $\mu \mathrm{g} \cdot \mathrm{kg}^{-1}$ de pipécuronium lors d'une anesthésie au thiopental, protoxyde d' azose et halothane. Lorsque la force de contraction atteignait $20 \%$ de la valeur contrôle lors de sa récupération spontanée, nous injections de l'édrophonium selon le protocole suivant. Aux patients des groupes I et II, nous en injections I $\mathrm{mg} \cdot \mathrm{kg}^{-1}$ et d̀ ceux des groupes III et IV, $0,75 \mathrm{mg} \cdot \mathrm{kg}^{-1}$. Pourles patients des groupes I et III, I' injection se faisait d' un seul coup, tandis que pour ceux des groupes III et IV, on injectait d'abord $0,25 \mathrm{mg} \cdot \mathrm{kg}^{-1}$ suivi du reste de la dose trois minutes plus tard. La fragmentation de la dose d'édrophonium entraîna une récupération plus rapide de la force de contraction musculaire (a partir de l'injection de la fraction initiale). Ainsi, dix minutes post injection, le ratio du train-de-quatre ondes (TOF) dépassait 0,75 chez 12 (100\%) et chez dix (83\%) des patients des groupes II et IV. D'ailleurs, le temps de latence avant d'arriver d un ratio de 0,75 élait en moyenne plus court chez les patients à dose fractionnée que chez les autres $(P<0,05)$ soit 354.5 (erreur type: 38,7$)$ et $398,3(49,1)$ secondes pour les groupes II et IV d'une part et $705,4(66,6)$ et $651,2(54,3)$ secondes pour les groupes I et III d'autre part. Dans un contexte de bloc neuromusculaire résiduel au pipécuronium, la fragmentation de la dose d'édrophonium utilisée comme antidote en augmente l'efficacité et en accélère l'action. 
Pipecuronium bromide is a new long-acting, nondepolarizing muscle relaxant which is devoid of cardiovascular effects.' Wierda et al. ${ }^{2}$ noted the variability in response to edrophonium $0.5-0.75 \mathrm{mg} \cdot \mathrm{kg}^{-1}$ during reversal of residual pipecuronium-induced neuromuscular blockade. We found that edrophonium in a dose of $1 \mathrm{mg} \cdot \mathrm{kg}^{-1}$ does not consistently antagonize neuromuscular blockade induced by pipecuronium when edrophonium was given at $20 \%$ recovery of the first twitch $\left(\mathrm{T}_{1}\right)$ of the train-of-four (TOF) stimulation. ${ }^{3}$

We have demonstrated previously that a marked acceleration of recovery of atracurium neuromuscular blockade could be achieved with the administration of edrophonium in divided doses. ${ }^{4-8}$

This study was designed to determine whether divided administration of different doses of edrophonium could alter the course of neuromuscular recovery from a pipecuronium neuromuscular blockade.

\section{Methods}

After institutional approval, 48 ASA physical status I or II adult patients of either sex were studied. All patients were undergoing elective procedures, were free of neuromuscular, renal or hepatic disease and were not taking any drug known to interfere with neuromuscular function. Informed consent was obtained. All patients received $10-15 \mathrm{mg}$ diazepam po $90 \mathrm{~min}$ preoperatively.

An intravenous infusion of lactated Ringer's solution was established prior to induction. The ECG and nasopharyngeal temperature were monitored continuously. Body temperature varied less than $0.5^{\circ} \mathrm{C}$ range throughout the studies. Blood pressure was measured every five minutes by an electronic oscillometer (Dinamap, Critikon, Inc., Tampa, USA).

In all patients, anaesthesia was induced with fentanyl 2 $\mu \mathrm{g} \cdot \mathrm{kg}^{-1}$, thiopentone $5 \mathrm{mg} \cdot \mathrm{kg}^{-1}$, and was maintained with 70 per cent nitrous oxide in oxygen and halothane (0.5-1 per cent). Inspired halothane concentration and end-tidal $\mathrm{CO}_{2}$ were monitored by a Datex Capnomac monitor (Datex Instrumentarium, Helsinki, Finland). Ventilation was adjusted to maintain normocapnia (PET$\mathrm{CO}_{2} 35-40 \mathrm{mmHg}$ ).

The ulnar nerve was stimulated at the wrist with square wave supramaximal stimuli of $0.2 \mathrm{~ms}$ duration, delivered in a train-of-four (TOF) sequence at $2 \mathrm{~Hz}$ every ten seconds, using a Myotest peripheral nerve stimulator (Biometer International, Odense, Denmark). The resultant contraction of the adductor pollicis was recorded using a force displacement transducer and neuromuscular function analyzer (Myograph 2000, Biometer International, Odense, Denmark.) ${ }^{9}$ Preload tension of the thumb was maintained at $300 \mathrm{~g}$ throughout the investigation.
After stabilization of the twitch recording, pipecuronium $70 \mu \mathrm{g} \cdot \mathrm{kg}^{-1}$ was administered and tracheal intubation was performed at maximum block. Patients were excluded from the study if additional doses of pipecuronium were given.

At the end of surgery, when the first twitch $\left(T_{1}\right)$ of the TOF had returned to $20 \%$ of control value, patients were randomly allocated to four groups ( $n=12$ in each) to receive either edrophonium $I \mathrm{mg} \cdot \mathrm{kg}^{-1}$ (Groups I and II) or edrophonium $0.75 \mathrm{mg} \cdot \mathrm{kg}^{-1}$ (Groups III and IV). In Groups I and III edrophonium $1.0 \mathrm{mg} \cdot \mathrm{kg}^{-1}$ and 0.75 $\mathrm{mg} \cdot \mathrm{kg}^{-1}$ respectively was administered in a single bolus dose. In Groups II and IV edrophonium was administrated as an initial dose of $0.25 \mathrm{mg} \cdot \mathrm{kg}^{-1}$ followed three minutes later by either 0.75 or $0.50 \mathrm{mg} \cdot \mathrm{kg}^{-1}$ respectively. In all patients atropine $0.02 \mathrm{mg} \cdot \mathrm{kg}^{-1}$ was administered prior to edrophonium.

Patients continued to receive $70 \%$ nitrous oxide in oxygen and $0.5-1 \%$ halothane until all measurements were complete. Antagonism of block was considered adequate when a TOF ratio (the amplitude of the fourth to the first evoked response; $T_{4} / T_{1}$ ) of 0.75 was attained. ${ }^{10}$ Additional doses of edrophonium $0.25 \mathrm{mg} \cdot \mathrm{kg}^{-1}$ were given at 10 and $15 \mathrm{~min}$ if the TOF ratio had not reached 0.75 . Further assessment of the patients was carried out in the Recovery Room for 60 minutes, using clinical criteria such as the ability to open eyes, cough and sustain a head lift.

The following variables were calculated:

(a) Time from the end of injection of pipecuronium to $20 \%$ recovery of $\mathrm{T}_{1}$ (clinical duration);

(b) Time from injection of the edrophonium until first increase of the twitch was observed (onset time);

(c) TOF ratio three minutes after first administration of edrophonium (just before the administration of the second dose in Groups II and IV);

(d) Times to attain TOF ratios of $0.25,0.5$ and 0.75 ;

(e) TOF ratio and $T_{1}$ value (\% control) versus time after first administration of edrophonium;

(f) TOF ratio at ten minutes; and

(g) The TOF ratio at $20 \%$ increments of $T_{1}$ tension recovery.

Time was counted from the first administration of edrophonium.

\section{Data processing}

Statistical analyses were performed by the BMDP (1990) statistical package (University of California Press). Differences between groups were evaluated with analysis of variance. A Student-Newman-Keuls test was used whenever statistically significant differences were obtained.

We also tested the hypothesis that recovery variables 
TABLE Onset time, train-of-four (TOF) ratio $3 \mathrm{~min}$ after the administration of edrophonium, times to attain different TOF ratios and TOF ratio al $10 \mathrm{~min}($ mean $\pm S E M)$

\begin{tabular}{|c|c|c|c|c|c|c|c|}
\hline \multirow[b]{2}{*}{ Groups } & \multirow{2}{*}{$\begin{array}{l}\text { Onset time\$ } \\
\text { (sec) }\end{array}$} & \multirow{2}{*}{$\begin{array}{l}\text { TOF ratio } 3 \text { min after } \\
\text { first administration } \\
\text { of edrophonium }\end{array}$} & \multicolumn{3}{|c|}{ Times (sec) to allain TOF ratio of } & \multirow{2}{*}{$\begin{array}{l}\text { TOF ratio al } \\
10 \mathrm{~min}\end{array}$} & \multirow{2}{*}{$\begin{array}{l}\text { Dose } \\
m g \cdot \mathrm{kg}^{-1}\end{array}$} \\
\hline & & & 0.25 & 0.50 & 0.75 & & \\
\hline \multicolumn{8}{|l|}{ Group I (edrophonium } \\
\hline ( $\mathrm{mg} \cdot \mathrm{kg}^{-1}-$ single dose) & $22.1 \pm 3.6^{*}$ & $0.59 \pm 0.02 \dagger$ & $36.2 \pm 5.5$ & $108.7 \pm 25.3$ & $705.4 \pm 66.5$ & $0.72 \pm 0.02$ & $1.187 \pm 0.05 \dagger$ \\
\hline \multicolumn{8}{|l|}{ Group II (edrophonium } \\
\hline $\mathrm{I} \mathrm{mg} \cdot \mathrm{kg}^{-1}-$ divided doses) & $37.9 \pm 2.9$ & $0.42 \pm 0.02$ & $55.4 \pm 3.7$ & $206.6 \pm 6.2 \ddagger$ & $354.5 \pm 38.7 \ddagger$ & $0.83 \pm 0.01 \ddagger$ & $1 \pm 0$ \\
\hline \multicolumn{8}{|l|}{$\begin{array}{l}\text { Group Ill (edrophonium } \\
0.75 \mathrm{mg} \cdot \mathrm{kg}^{-1}-\text { single }\end{array}$} \\
\hline \multicolumn{8}{|l|}{$\begin{array}{l}\text { Group IV (edrophonium } \\
0.75 \mathrm{mg} \cdot \mathrm{kg}^{-1}-\text { divided }\end{array}$} \\
\hline doses) & $36.2 \pm 3.7$ & $0.47 \pm 0.03$ & $53.2 \pm 6.3$ & $170.8 \pm 16.8$ & $398.3 \pm 49.1 \ddagger$ & $0.82 \pm 0.02 \ddagger$ & $0.792 \pm 0.02$ \\
\hline
\end{tabular}

were not different whether edrophonium was administered in a single dose (Groups I and III) or in priming (divided) doses (Groups II and IV). The null hypothesis tested (using Scheffe's linear combination method) was:

$\mu_{1}-\mu_{2}+\mu_{3}-\mu_{4}=0$.

For all statistical comparisons, differences were considered significant when $P<0.05$.

\section{Results}

The results are expressed as means (SEM). The four groups of patients did not differ significantly with respect to age, body weight, or sex. Their mean age and body weight were $31.9(1.5)$ yr and $63.6(1.6) \mathrm{kg}$.

The clinical duration of the $70 \mu \mathrm{g} \cdot \mathrm{kg}^{-1}$ dose of pipecuronium was $60.9(2.2), 63.6(3), 64.1$ (2.4), and 62 (2.1) $\mathrm{min}$ in Group I to IV respectively.

Onset time following the administration of edrophonium $1 \mathrm{mg} \cdot \mathrm{kg}^{-1}$ as a single dose in Group I was significantly shorter compared to other groups (Table).

The TOF recovery was initially slower when edrophonium was given in divided doses (Figure 1). Three minutes after first administration of edrophonium (just before the administration of the second dose in Groups Il and IV), the mean TOF ratios were $0.59(0.02)$ and $0.58(0.01)$ in Groups I and III respectively (single-dose groups). This was greater than the $0.42(0.02)$ and $0.47(0.03)$ in groups II and IV respectively (divided-dose groups). However, administration of the second dose of edrophonium to the latter groups at that time resulted in a faster recovery of the
TOF ratio between 5 and $10 \mathrm{~min}$ (Figure 1). Similarly times to attain a TOF ratio of 0.75 were significantly shorter in divided-dose groups than in single-dose groups (Table).

After three minutes, before giving the second dose of edrophonium, $T_{1}$ recovery was greater in the single-dose groups than in Group II (Figure 2). Between four and ten minutes after first administration of edrophonium, no statistically significant differences were found in $T_{1}$ recovery among the groups.

At ten minutes after reversal, TOF ratio recovery reached 0.75 or more in $12(100 \%)$ and in ten $(83 \%)$ patients in Groups II and IV respectively (divided-dose groups) (Figure 3 ). In contrast, the same degree of recovery was reached in five $(42 \%)$ and in one $(8 \%)$ patients in Groups I and III respectively (single-dose groups).

Administration of one additional dose of edrophonium $\left(0.25 \mathrm{mg} \cdot \mathrm{kg}^{-1}\right)$ resulted in adequate antagonism (TOF ratio of 0.75 ) in the remaining two patients in Group IV and in five and three patients in Groups I and III respectively. Two such doses were required in the remaining two and eight patients in Groups I and III respectively (single-dose groups).

The mean total doses of edrophonium employed in this study were $1.187(0.05), I(0), 1.146(0.04)$ and 0.792 $(0.02) \mathrm{mg} \cdot \mathrm{kg}^{-1}$ in Group I to IV respectively. The total doses were significantly greater in single-dose groups compared to divided-dose groups.

The mean values of TOF ratio for $20 \%$ increments of $T_{1}$ 


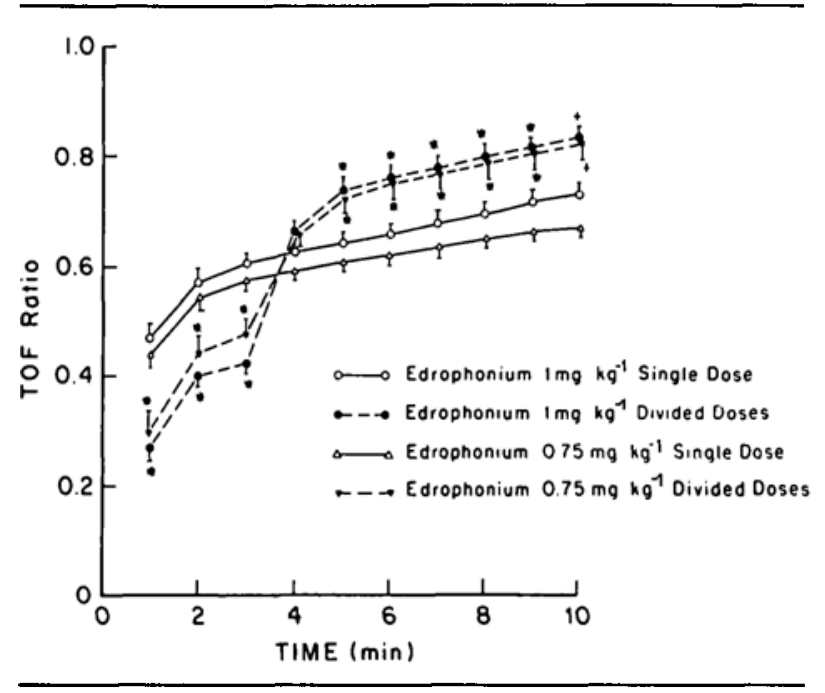

FIGURE I Train-of-four (TOF) ratio against lime after first administration of edrophonium, for patients who received the drug in single and divided doses. Error bars represent standard error of the mean (SEM). ${ }^{*} P<0.05,+P<0.01$ vs single-dose groups.

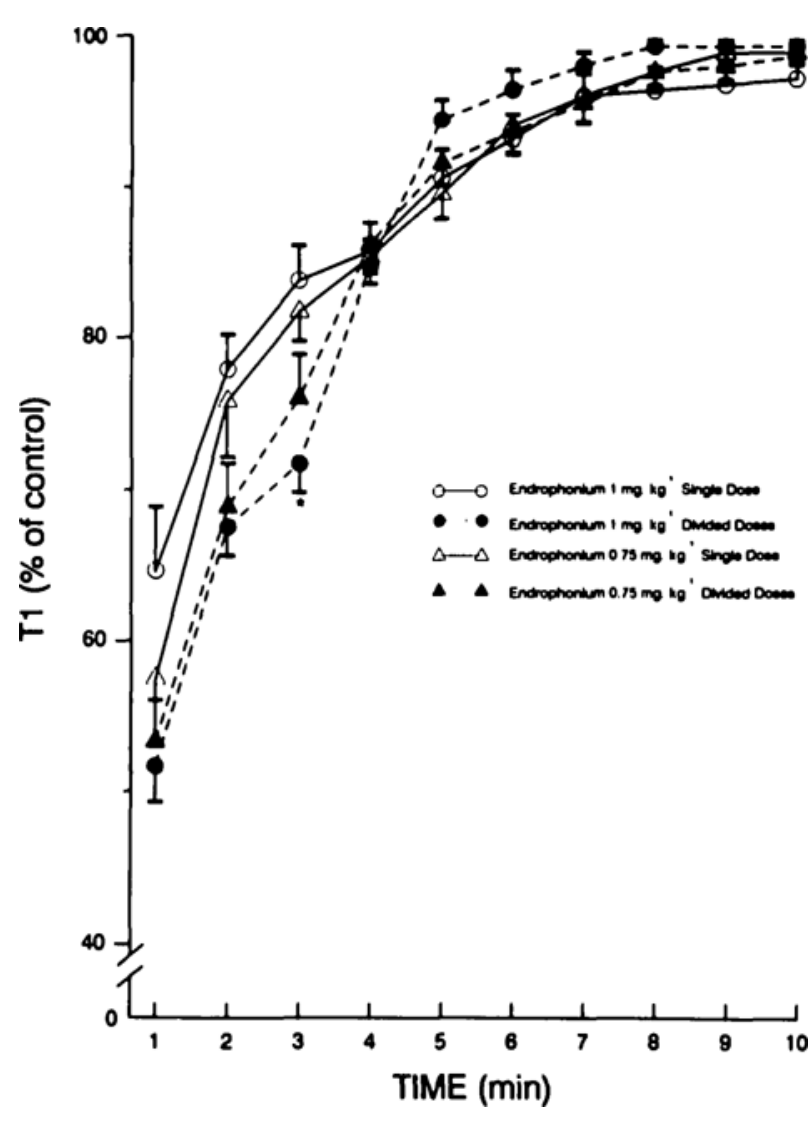

FJGURE 2 First twitch height $\left(T_{1}\right)$ as \% of control against time after furst administration of edrophonium, for patients who received the drug in single and divided doses. Error bars represent standard error of the mean (SEM). ${ }^{*} P<0.05$ vs single-dose groups.

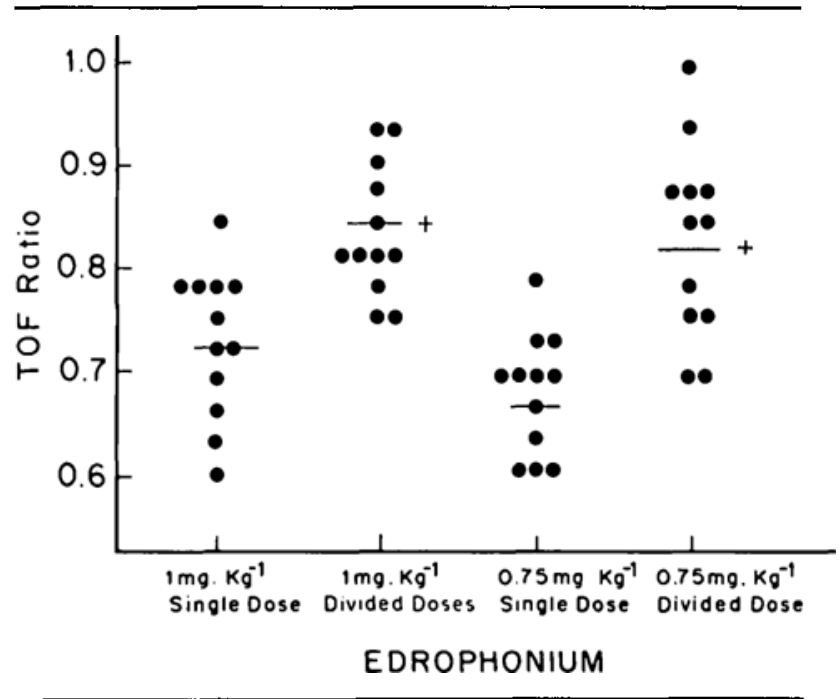

FIGURE 3 Train-of-four (TOF) ratio in individual patients ten minutes after administration of edrophonium. $(-)$ Indicates the mean for the groups. Circles represent individual patients. + Indicates significant difference $(P<0.01)$ from the single-dose groups.

are shown for each group in Figure 4 . When $T_{1}<80 \%$ of control, a greater recovery of TOF ratio was observed in Group I. In contrast, at $T_{1}=100 \%$ of control, TOF ratio was greater $(P<0.05)$ in the divided-dose groups being $0.72(0.02)$ and $0.74(0.02)$ (in Groups II and IV) compared with $0.65(0.02)$ and $0.62(0.02)$ in Groups I and III respectively (single-dose group).

\section{Discussion}

In this study, we demonstrated that recovery from pipecuronium neuromuscular blockade can be accelerated significantly by divided (priming) administration of edrophonium. This acceleration of recovery was noted during antagonism of atracurium blockade as well. ${ }^{4-7}$ Donati et al. found that divided administration anticholinesterases did not result in acceleration of recovery of atracurium blockade. ${ }^{11,12}$ Others administered repeated doses of neostigmine ( $70 \mu \mathrm{g} \cdot \mathrm{kg}^{-1}$ each) in the presence of profound vecuronium neuromuscular blockade and concluded that repeated administration of neostigmine provided no evidence of hastened recovery. ${ }^{13}$

We reviewed the previous studies ${ }^{1-13}$ in an attempt to find possible explanations for the difference in the results obtained. The most striking differences were in the anaesthetic techniques used, the stimulation frequencies, the level of block at which anticholinesterases were administered, size and time interval between the two doses of the antagonist, and the way in which data were analyzed. We believe that these differences can explain many of the reported differences ${ }^{4-8,11-13}$ for the following reasons. First, in the studies reported by Donati et 


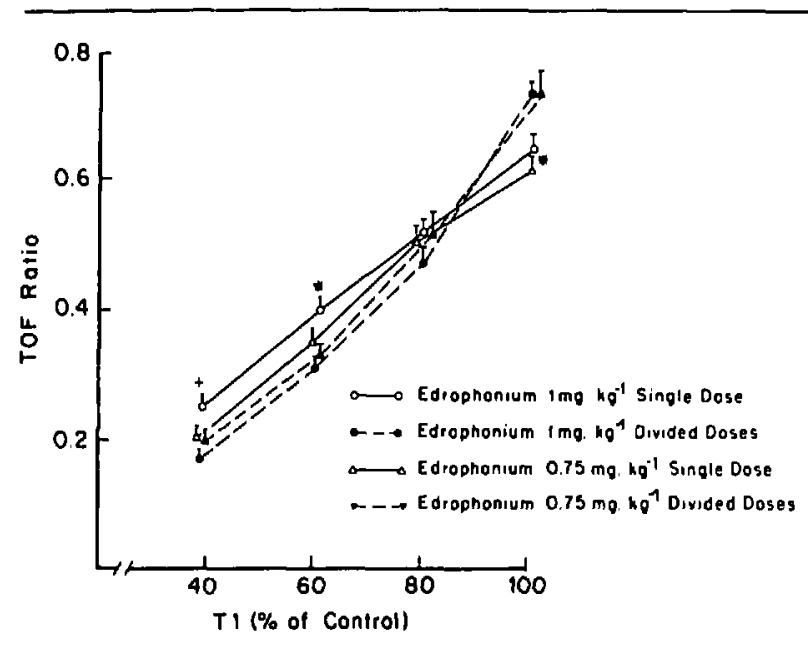

FIGURE 4 Relationship of train-of-four (TOF) ratio and first Iwitch tension $(T$, during the antagonism of residual pipecuronium blockade after administration of edrophonium in a single dose (Groups I and III) or in divided (priming) sequence (Groups II and IV). Error bars represent standard error of the mean (SEM). $+P<0.05$ vs other groups $* P<0.05$ vs divided-dose groups

al. ${ }^{11,12}$ which demonstrated no acceleration of reversal with neostigmine or edrophonium priming, the inhalational agent used was enflurane instead of halothane. Enflurane, unlike halothane, is known to impair neostigmine $^{14}$ or edrophonium ${ }^{15}$ assisted recovery. Miller et al. ${ }^{16}$ pointed out that the interaction of muscle relaxants with different anaesthetics may occur by different mechanisms.

Secondly, in our previously published reports with respect to edrophonium priming, ${ }^{4-7}$ we administered edrophonium at $10 \%$ recovery of $T_{1}$. Donati et al. ${ }^{12}$ administered edrophonium when $T_{1}$ had recovered to a mean value (SEM) of $10.6 \%(1.0 \%)$ of control. This represents a standard deviation of 3.162. In other words, some of their patients were given edrophonium when $T_{\text {I }}$ had recovered to approximately $6.8 \%$ (mean - 1 SD) of control value. The same group has reported ${ }^{17}$ previously that the effectiveness of edrophonium was found to be critically dependent on the intensity of the block at the time it was administered. Thirdly, the number of patients ( $n=20$, divided into two groups) included in the study reported by Donati et al. ${ }^{12}$ was sufficient to detect a difference of $10 \%$ or more. Nevertheless, they noted a greater recovery in TOF ratio (a $9 \%$ difference) at seven minutes in patients who had received edrophonium in divided doses. Perhaps increasing the number of patients included in that study ${ }^{12}$ could have affected the results.

In addition, the study reported by Magorian and colleagues $^{13}$ bears no resemblance to our reported studies. $^{4-7}$ They administered the first dose of neostigmine $\left(70 \mu \mathrm{g} \cdot \mathrm{kg}^{-1}\right)$ during profound vecuronium blockade (no twitch) and the second dose when $T_{1}$ had recovered to $10 \%$ of control value and concluded that repeated administration of neostigmine does not alter the course of recovery. ${ }^{13}$

In this study we tried to answer a specific question does administration of edrophonium in divided doses result in a noticeable acceleration of recovery over a single dose of the drug? Rather than using multiple comparisons, we tested the hypothesis directly using Scheffe's linear combination method. Our results indicated that there was a highly significant increase in TOF recovery in divided dose groups vs single dose groups (Figure 1). Also of note is that administration of a smaller dose of edrophonium in divided doses $\left(0.75 \mathrm{mg} \cdot \mathrm{kg}^{-1}\right)$, in Group IV was more effective than the single administration of a larger dose $\left(1 \mathrm{mg} \cdot \mathrm{kg}^{-1}\right.$, Group I). For example, time to attain TOF ratio of 0.75 were $705.4 \mathrm{sec}(11.7 \mathrm{~min}$ ) vs $398.3 \mathrm{sec}(6.6 \mathrm{~min})$ and TOF ratios at ten minutes were 0.72 vs 0.82 in Groups I and IV respectively (Table). Furthermore, the mean total doses of edrophonium employed in this study were significantly greater in the single-dose groups than in the divided-dose groups.

Donati et al. ${ }^{11.12}$ suggested that the time to an arbitrarily defined end-point (TOF of 0.75 ) could result in a disproportionate shortening of reversal time and indicated that TOF ratio should be plotted against time in order to demonstrate changes with respect to time. A TOF ratio of 0.75 is usually considered as an indication of adequate recovery from a neuromuscular blockade. ${ }^{10}$ Nevertheless, Figure 1 clearly demonstrates the difference in TOF recovery between divided-dose groups vs single-dose groups.

It is beyond the scope of the current study to address the possible mechanisms involved. ${ }^{4-8.11,12}$ Donati et al. ${ }^{11,12}$ proposed that muscle contraction-induced changes in the blood flow could explain the effectiveness of priming with anticholinesterases. They suggested that the priming dose of edrophonium produces sufficient recovery of neuromuscular activity to be associated with considerable muscle contraction. Thus, muscle oxygen requirement is likely to be greater. It follows that blood flow is probably also greater, to keep up with metabolic demand. Increased muscle blood flow would increase delivery of the second (and the larger) dose of the drug to the muscle and thereby accelerate the recovery. We suggested earlier ${ }^{4-8}$ that a reduction in the "margin of safety" 18 of acetylcholinesterase enzyme could explain this phenomenon. Another possible explanation is related to the differential prejunctional activity of edrophonium priming at the neuromuscular junction. In an earlier study, ${ }^{7}$ we noted that this differential ability to reverse fade was involved in the acceleration of recovery following administration of edrophonium in divided doses. In the current study, when first twitch tension $\left(T_{1}\right)$ had recovered to $100 \%$ of the 
control, it was found for the same tension that TOF ratios were greater $(P<0.05)$ in divided-dose groups than in the single-dose groups (Figure 4). Nevertheless, the question at hand should be answered by monitoring miniature end-plate potentials with both techniques of drug administration (single vs divided).

Whether it is appropriate to administer edrophonium in divided doses is a relevant clinical consideration. The results of this study, when compared with our previously reported results, ${ }^{3}$ confirm that administration of edrophonium in a single dose (Groups I and III) did not consistently antagonize residual neuromuscular blockade induced by pipecuronium at $20 \%$ recovery of $T_{1}$. While edrophonium is known to be a less reliable antagonist of moderate to deep levels of neuromuscular blockade than neostigmine, ${ }^{3}$ we have demonstrated in this study that divided administration of the edrophonium could alter the course of neuromuscular recovery from a pipecuroniuminduced neuromuscular blockade.

We conclude that when reversal was attempted at $20 \%$ recovery after a single bolus dose of pipecuronium, divided administration of edrophonium not only accelerated the recovery of residual neuromuscular blockade, but also reduced the requirements of the edrophonium needed for adequate reversal of the block.

\section{Acknowledgements}

The authors gratefully acknowledge the assistance of Ms. Pamela Roberts and Mr. David Liewald. Pipecuronium was supplied by Organon Teknika, Belgium.

\section{References}

1 Boros M, Szenohradszky J, Kertesz A, Marosi CY, Tutsek $L$. Clinical experiences with pipecuronium bromide. Acta Chir Hung 1983; 24: 207-14.

2 Wierda JMKH, Richardson FJ, Agoston S. Dose-response relation and time course of action of pipecuronium bromide in humans anesthetized with nitrous oxide and isoflurane, halothane, or droperidol and fentanyl. Anesth Analg 1989; 68: 208-13.

3 Abdulatif $M$, Naguib $M$. Neostigmine and edrophonium for reversal of pipecuronium neuromuscular blockade. Can J Anaesth 1991; 38: 159-63.

4 Naguib $M, A$ Adulatif $M, A b s o o d G H$. Accelerated reversal of atracurium blockade with priming doses of edrophonium. Anesthesiology 1987; 66: 397-400.

5 Naguib $M$, Abdulatif $M$. Priming with anticholinesterases - the effect of different combinations of anticholinesterases and different priming intervals. Can J Anaesth 1988; 35: 47-52.

6 Naguib $M$, Abdulatif $M$. Priming with anticholinesterases - the effect of different priming doses of edrophonium. Can J Anaesth 1988; 35: 53-7.
7 Naguib M. Train-of-four ratio after antagonism of atracurium with edrophonium: influence of different priming doses of edrophonium. Can J Anaesth 1989; 36: 25-9.

8 Abdulatif $M$, Naguib $M$. Accelerated reversal of atracurium blockade with divided doses of neostigmine. Can Anaseth Soc J 1986; 33: 723-8.

9 Viby-Mogensen J. Clinical assessment of neuromuscular transmission. Br J Anaesth 1982; 54: 209-23.

$10 \mathrm{Ali} H \mathrm{H}, \mathrm{Kitz}$ RJ. Evaluation of recovery from nondepolarizing neuromuscular block using a digital neuromuscular transmission analyzer: preliminary report. Anesth Analg 1973; 52: 740-5.

11 Donati F, Smith CE, Wiesel S, Bevan DR. "Priming" with neostigmine: failure to accelerate reversal of single twitch and train-of-four responses. Can J Anaesth 1989; 36: 30-4.

12 Szalados JE, Donati $F$, Bevan DR. Edrophonium priming for antagonism of atracurium neuromuscular blockade.

Can J Anaesth 1990; 37: 197-201.

13 Magorian TT, Lynam DP, Caldwell JE, Miller RD. Can early administration of neostigmine, in single or repeated doses, alter the course of neuromuscular recovery from a vecuronium-induced neuromuscular blockade? Anesthesiology 1990; 73: 410-4.

14 Delisle S, Bevan DR. Impaired neostigmine antagonism of pancuronium during enflurane anaesthesia in man. $\mathrm{Br} J$ Anaesth 1982; 54: 441-5.

15 Dernovoi B, Agoston S, Baurain M, Lefebure R, d'Hollan$\operatorname{der} A$. Neostigmine antagonism of vecuronium paralysis during fentanyl, isoflurane, and enflurane anesthesia. Anesthesiology 1987; 66: 698-701.

16 Miller RD, Way WL, Donlan WM, Stevens WC, Eger II $E I$. The dependence of pancuronium- and dtubocurarine-induced neuromuscular blockades on alveolar concentrations of halothane and forane. Anesthesiology 1972; 37: 573-81.

17 Donati F, Smith CE, Bevan DR. Dose-response relationships for edrophonium and neostigmine as antagonists of moderate and profound atracurium blockade. Anesth Analg 1989; 68: 13-9.

18 Barber $H E$, Calvey $T N$, Muir KT. The relationship between the pharmacokinetics, cholinestrase inhibition and facilitation of twitch tension of the quaternary ammonium anticholinesterase drugs neostigmine, pyridostigmine, edrophonium and 3-hydrophenyltrimethylammonium. Br J Pharmacol 1979; 66; 525-30. 